\title{
A Composite Evaluation Model of Sustainable Manufacturing in Machining Process for Typical Machine Tools
}

\author{
Lishu Lv ${ }^{1,2} \mathbb{C}$, Zhaohui Deng ${ }^{1,2, *}$, Tao Liu ${ }^{1,2}$, Linlin Wan ${ }^{1,2}$, Wenliang Huang ${ }^{1,2}$, Hui Yin ${ }^{1,2}$ \\ and Tao Zhao ${ }^{1,2}$ \\ 1 Hunan Provincial Key Laboratory of High Efficiency and Precision Machining of Difficult-to-Cut Material, \\ Hunan University of Science and Technology, Xiangtan 411201, China; ldlylls@163.com (L.L.); \\ ddyxxt1@163.com (T.L.); wanlinlin@hnust.edu.cn (L.W.); 15173298195@163.com (W.H.); \\ yin_123hui@163.com (H.Y.); zhaotao1662@sina.com (T.Z.) \\ 2 Intelligent Manufacturing Institute, Hunan University of Science and Technology, Xiangtan 411201, China \\ * Correspondence: edeng0080@vip.sina.com; Tel.: +86-731-5829-0411
}

Received: 30 December 2018; Accepted: 15 February 2019; Published: 20 February 2019

check for updates

\begin{abstract}
Machine tool is the basic manufacturing equipment in today's mechanical manufacturing industry. A considerable amount of energy and carbon emission are consumed in machining processes, the realization of sustainable manufacturing of machine tools have become an urgent problem to be solved in the field of industry and academia. Therefore, five types of machine tools were selected for the typical machining processes (turning, milling, planning, grinding and drilling). Then the model of the energy efficiency, carbon efficiency and green degree model were established in this paper which considers the theory and experiment with the resource, energy and emission modeling method. The head frame spindle and head frame box were selected to verify the feasibility and practicability of the proposed model, based on the orthogonal experiment case of the key machining process. In addition, the influence rules of machining parameters were explored and the energy efficiency and green degree of the machine tools were compared. Finally, the corresponding strategies for energy conservation and emission reduction were proposed.
\end{abstract}

Keywords: energy efficiency; carbon efficiency; green degree; typical machine tools; energy conservation and emission reduction

\section{Introduction}

With the continuous progress of society and the rapid development of economy, the problem of energy consumption and environmental impact are increasingly serious. Therefore, a new modern manufacturing mode-green manufacturing has been introduced. Green manufacturing, which gives a comprehensive consideration of environmental impact and resource consumptions, is also an important solution to solve the increasingly resource and environmental problems in manufacturing industry [1].

The International Academy for Production Engineering (CIRP) held its 26th International Manufacturing Conference with theme of Energy efficiency and low-carbon manufacturing at the University of Dublin, Ireland, In September 2009. The following issue: "In order to ensure the innovation and development of manufacturing industry, the energy consumption of manufacturing process and system must be accurately evaluated" has been put forward [2]. Therefore, the energy efficiency of machine tools, the quantitative calculation of carbon emissions and the study of carbon emission reduction theory are of particular concern.

Machine tools are the basic energy consumption devices in manufacturing. As a high-energy consumption product, reducing the energy consumption and negative impact of the machining 
process on the environment of machine tool processing can achieve green industrial upgrading for manufacturing enterprises. The study by Prof Gutowski showed that the carbon emissions of a numerical control machine tool with main shaft power in $22 \mathrm{~kW}$ operating one year was equivalent to the emissions of 61 SUV cars [3]. In European Union's Eco-design Directive, the machine tools have been regarded as the indicators of the regulatory priority categories [4]. Therefore, it is particularly important to seek guidance to improve the efficiency of machine tool, reduce energy consumption and improve carbon efficiency and environmental impact.

A perusal of current literatures concluded that the existing researches about green manufacturing of machine tools are mostly concentrated on energy consumption, carbon emission and resource environmental impact. And the lean energy saving and emission-reduction are promoted to sustainability manufacturing industry [5]. Research on the existing energy modeling of machine tools were focused on the following aspects: the energy consumption model based on material remove rate, processing parameters fitting or processing dynamic performance [6,7]. Gradually, researchers on the energy situation of machine tools begin to develop energy efficiency and specific energy consumption and the results showed that using these indicators can more effectively characterize the energy consumption status of machine tools [8-11].

Quantifying the carbon emission of machining process is an important step towards achieving low carbonization of mechanical manufacturing process. These studies are mainly composed of the static quantitative modeling analysis and dynamic quantitative modeling analysis. In the traditional static modeling analysis, the carbon emission is usually quantified through the whole life cycle evaluation and carbon footprint [12-14]. Considering the dynamic characteristics of the machining process, Li et al. [15] presented a carbon emission analysis model for electronics manufacturing process based on value-stream mapping and sensitivity analysis. Similarly, a carbon emission quantitation model and experimental evaluation was established for machining process under the considering of tool wear condition [16]. Li et al. [17] proposed an analytical method of quantifying carbon emissions of a computer numerical control (CNC)-based machining system. Meanwhile, in order to better describe the carbon emission characteristics, models such as carbon efficiency [18,19], carbon emission rate [20], carbon benefit [21] were starting to emerge.

The productivity, cost and quality pursued by the traditional production process are obviously not enough but the characteristic target of green manufacturing: environmental impact and resource consumption should be considered as important factors. How to determine the ecological compensation criterion reasonably have been recognized as a problem of improving the environment performance [22]. At present, the research mainly focuses on analyzing and evaluating the influence of resource environment consumed in the machining process $[23,24]$ and establishing the evaluation model of resource environment property $[25,26]$. Based on the established evaluation model, scholars evaluated the green conditions of the machine tools by using the method of fuzzy Analytic Hierarchy Process (AHP) or fuzzy comprehensive evaluation [27,28].

In conclusion, the study of green manufacturing is booming up. However, due to the machining particularity of different process, it is hard to evaluate the green performance of machine tools properly. While the current studies seem abundant and some significant studies on the quantitative analysis and evaluation of energy consumption, carbon emission and resource environment attribute has been performed in manufacturing system. But few efforts are received to analyze different machining process under the comprehensive green manufacturing evaluation model.

Given the lack of work in analyzing integrated composite evaluation model of sustainable manufacturing in machining process for typical machine tools, this paper fills this gap and studies combining experiments with theory, with the aim of energy conservation and emission reduction in machining processes, as shown in Figure 1. Section 2 analyzed the energy consumption, carbon emission, resource environment and other information in machining process and established the energy efficiency model, carbon efficiency model and green degree model. Section 3 presented the experimental results and determined the related index and weight of the proposed models. Section 4 
studied the influence of processing parameters, then presented the comparative analysis of energy efficiency, carbon efficiency and green degree and conducted the research on strategies of energy conservation and emission reduction. The conclusions will be discussed in Section 5 .

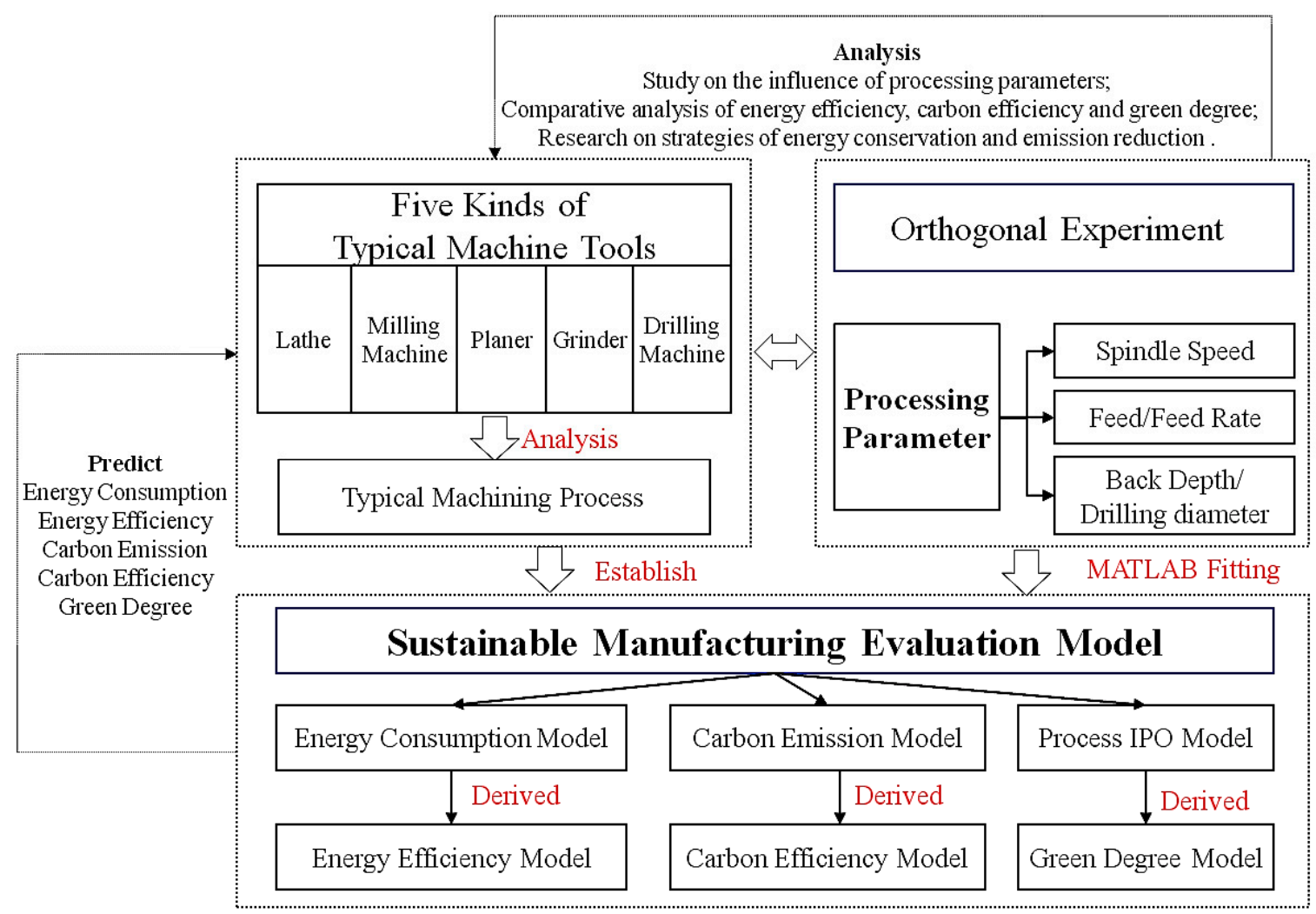

Figure 1. Research approaches.

\section{Composite Evaluation Model of Sustainable Manufacturing in Machining Process}

The resources consumption and the environmental pollutants generated during the machining process seriously hinder the development of sustainable manufacturing. Therefore, this paper mainly focuses on resource and environmental attributes, the energy efficiency, carbon efficiency and green degree are selected as the mainly indicators to describe the comprehensive green manufacturing evaluation model.

\subsection{Energy Efficiency Model}

The energy efficiency of mechanical processing system includes traditional energy efficiency, energy utilization efficiency and specific energy efficiency [29]. Energy efficiency modeling of mechanical systems can evaluate and analyze energy flow conditions for various machine tools and machining process. Meanwhile, many statistical surveys [30] showed that the energy efficiency of machine tools is less than $30 \%$. The traditional energy efficiency was used to express the energy efficiency of machine tool processing. Combined the research of energy efficiency [31], the function can be expressed as:

$$
\eta=\frac{E_{\text {cutting }}}{E_{\text {process }}}
$$

where $\eta$ is energy efficiency, $E_{\text {process }}$ is the total energy consumption of the machining process, $E_{\text {cutting }}$ is material removal energy consumption, which can be obtained based on cutting power and load state time $t_{\text {load }}$. 
From the processing state of $\mathrm{CNC}$ machine tools and the basic structure of $\mathrm{CNC}$ machine tools, the energy consumption of $\mathrm{CNC}$ machine tools can be decomposed into several modules (startup state, standby state, no-load state and load state), as shown in Figure 2. The total energy consumption and the material removal energy consumption of CNC machine tools are shown in Equation (2).

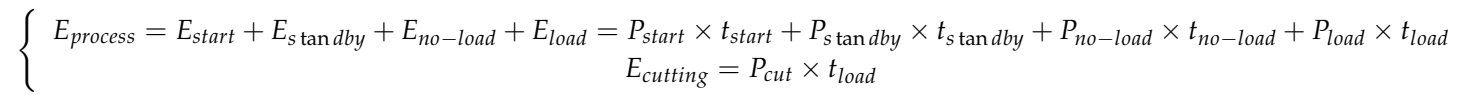

where $E_{s t a r t}, E_{s \tan d b y}, E_{n o-l o a d}, E_{\text {load }}$ are the starting state energy consumption, the standby state energy consumption, the no-load state energy consumption and the load state energy consumption. $P_{\text {start }}, P_{\text {stan dby }}, P_{\text {no-load }}, P_{\text {load }}, P_{\text {cut }}$ are the starting state power, the standby state power, the no-load state power, the load state power and the cutting power. $t_{s t a r}, t_{s \tan d b y}, t_{n o-l o a d}, t_{\text {load }}$ are the starting state time, the standby state time, the no-load state time and the load state time.

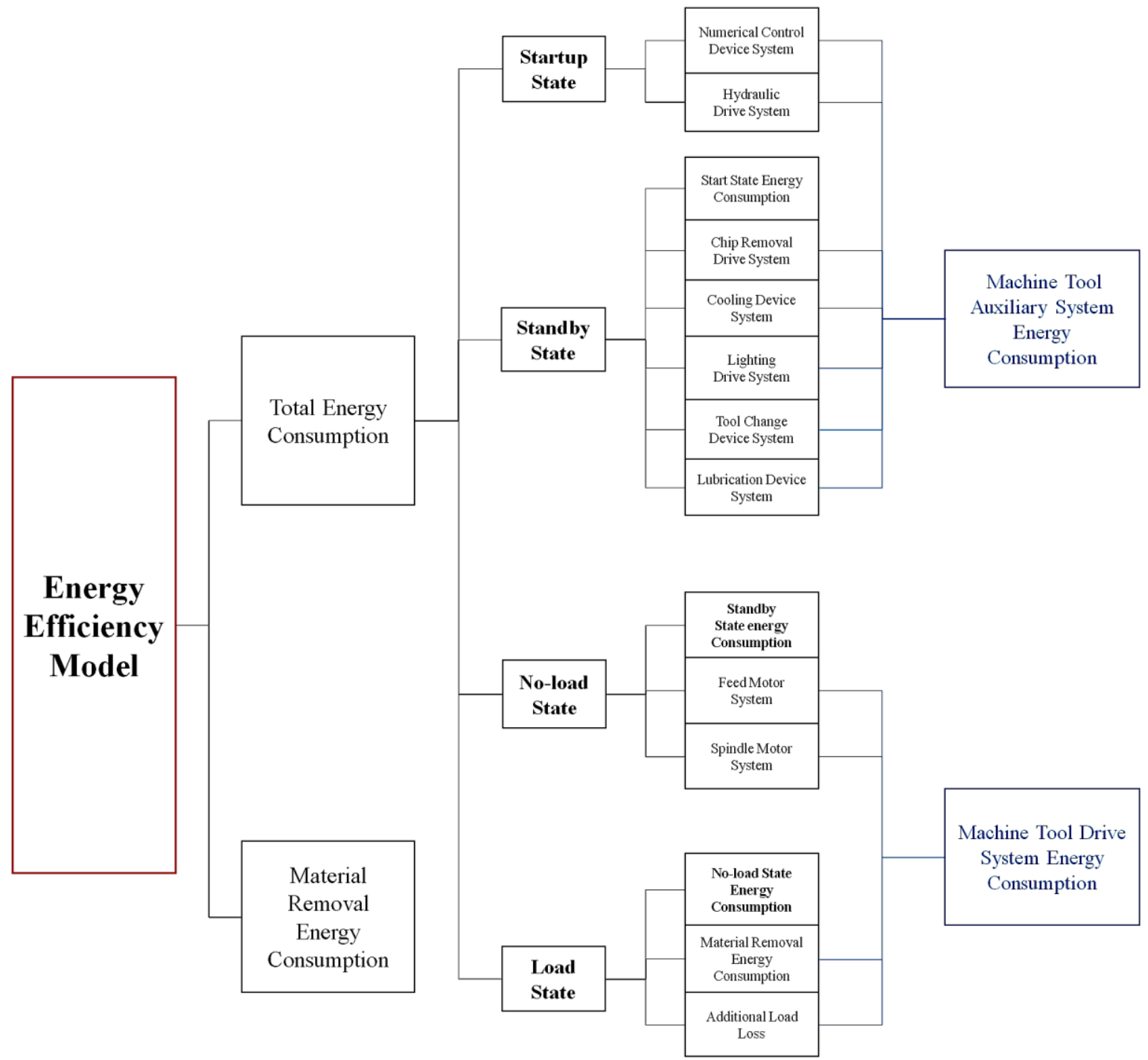

Figure 2. Energy efficiency model.

\subsubsection{Energy Consumption of Startup State}

Energy consumption of startup state is the energy consumed to maintain stable operation of machine tool after opening, which can be calculated by multiplying the basic power (CNC system power $P_{C N C}$ and the hydraulic system power $P_{\text {hydraulic }}$ ) and the system startup time. The basic power 
of the CNC system and the hydraulic system are determined by the rated power of the machine tool. The startup state power $P_{\text {start }}$ is expressed as follows:

$$
P_{\text {start }}=P_{\mathrm{CNC}}+P_{\text {hydraulic }}
$$

The running time of CNC device system and hydraulic device system run through the whole process of the machine tool. In the startup state, the running time is determined by the selected machine tool and the CNC program.

Therefore, the theoretical model of startup state energy consumption can be shown in Equation (4):

$$
E_{\text {start }}=P_{\text {start }} t_{\text {start }}=\left(P_{C N C}+P_{\text {hydraulic }}\right) t_{\text {start }}
$$

\subsubsection{Energy Consumption of Standby State}

Energy consumption of standby state is the energy required to turn on other auxiliary systems for stable operation, which can be calculated by multiplying the basic power (CNC system, hydraulic system, lighting drive system, chip removal drive system, tool changing drive system, cooling drive system, lubrication drive system) and the system startup time. The power of mechanical auxiliary system is basically stable, which can be known from the performance of machine tool. The energy consumption of another auxiliary device system is modeled by introducing switch function. The standby state energy consumption can be shown in Equation (5):

$$
E_{s \tan d b y}=E_{C N C}+E_{\text {hydraulic }}+E_{\text {light }}+E_{\text {chip }}+E_{\text {tool }}+E_{\text {cooling }}+E_{\text {lubricant }}=\left(P_{\text {CNC }}+P_{\text {hydraulic }}\right) t_{s t a n d b y}+\sum_{k=0}^{m} \xi(k) P_{k} t_{k}
$$

where, $E_{C N C}$ is the standby energy consumption of the CNC device system; $E_{\text {hydraulic }}$ is the standby energy consumption of the hydraulic system; $E_{\text {light }}$ is the energy consumption of the lighting system; $E_{\text {chip }}$ is the energy consumption of the chip removal device system; $E_{t o o l}$ is the energy consumption of tool changing device system; $E_{\text {cooling }}$ is the energy consumption of the cooling system; $E_{\text {lubricant }}$ is the energy consumption of lubricating device system; $\xi(k)$ denotes the working state of the auxiliary system $\xi(k)=\left\{\begin{array}{c}0, \text { stop } \\ 1, \text { run }\end{array} ; P_{k}\right.$ is the stable operating power of an auxiliary system; $t_{k}$ is the running time of an auxiliary system.

\subsubsection{Energy Consumption of No-Load State}

Energy consumption of no-load state is the energy consumed to maintain start spindle motor and feed servo motor after the machine tool support system stabilized, which can be calculated by multiplying the standby state energy consumption combined with spindle motor and feed motor systems power and the system no-load running time.

The basic power of the spindle motor system $P_{\text {spindle }}$ consists of the spindle motor loss power $P_{s-\text { friction }}$ and the spindle motor output power $P_{s-o u t}$. Spindle motor friction loss power is nearly constant and the spindle motor output power is the work done by the spindle motor in no-load operation to overcome its own friction force, which can be replaced by a constant $\omega$. The power of spindle motor system can be represented as:

$$
P_{\text {spindle }}=P_{s-\text { friction }}+\omega n
$$

where, $n$ is the spindle speed.

The basic power of feed motor $P_{\text {feed }}$ consists of feed servo motor loss power $P_{f-\text { friction }}$ and each axis feed servo motor output power $P_{f-o u t}$. Feed servo motor loss power can approximate as a stable value and the feed servo motor output power is the work done by the feed component to overcome 
the friction force during the feed motion, which can be replaced by a constant $\xi$, the power of feed motor system can be represented as:

$$
P_{\text {feed }}=P_{f-\text { friction }}+\xi v_{f}
$$

Therefore, the no-load state energy consumption model can be shown as follows:

$$
E_{n o-l o a d}=P_{n o-l o a d} t_{n o-l o a d}=\left(P_{C N C}+P_{\text {hydraulic }}+P_{\text {spindle }}+P_{\text {feed }}\right) t_{n o-l o a d}=\left(\omega n+\xi v_{f}+C\right) \frac{L_{n o-l o a d}}{v_{f}}
$$

where $C=P_{C N C}+P_{\text {hydraulic }}+P_{s-\text { friction }}+P_{f-\text { friction }}$.

\subsubsection{Energy Consumption of Load State}

Energy consumption of load state is the energy consumed when the tool comes into contact with the workpiece and material removal after the machine spindle motor and feed servo motor reach stability, which can be calculated by multiplying the no-load energy consumption combined with the basic power of material removal and additional load loss and the system load running time.

The material removal power is the effective power of machine tool output, which is related to the processing parameters. The process parameters of various typical processing methods are not completely consistent. In this paper, turning process was taken as an example as shown in Equation (9).

$$
P_{c u t}=C_{t F} a_{p}^{x 1} v_{f}^{y 1} v_{c}^{z 1} K_{t F}
$$

where $P_{c u t-c u t}$ is the material removal power in turning process; $v_{c}$ is the turning speed; $a_{p}$ is the back cutting depth; $C_{t F}, x 1, y 1, z 1, K_{t F}$ represent the coefficients and indexes related to turning.

The power measurement process of additional load loss is very numerous and complex, which is difficult to calculate directly under normal conditions [32]. It is pointed out that the additional load loss power $P_{\text {loss }}$ is approximately proportional to the material removal power $P_{c u t}$ according to the literature [33] on the energy consumption characteristics of machine tools, as shown below.

$$
P_{\text {loss }}=0.2 P_{\text {cut }}
$$

Load time $t_{\text {load }}$ can be determined by the material removal volume and material removal rate, as shown in Equation (11).

$$
t_{\text {load }}=M R V / M R R
$$

where $M R V$ is the material removal volume; $M R R$ is the material removal rate.

The load state energy consumption model is shown in the following equation:

$$
E_{\text {load }}=P_{\text {load }} t_{\text {load }}=\left(P_{\mathrm{CNC}}+P_{\text {hydraulic }}+P_{\text {spindle }}+P_{\text {feed }}+P_{\text {cut }}+P_{\text {loss }}\right) t_{\text {load }}=\left(\omega n+\tilde{\xi}_{f}+\mathrm{C}+1.2 P_{\text {cut }}\right) \frac{\mathrm{MRV}}{\mathrm{MRR}}
$$

Synthesizing the Equations (1)-(12), the energy efficiency model could be established as the following Equation (13).

$$
\eta=\frac{E_{\text {cutting }}}{E_{\text {process }}}=\frac{\left(P_{\text {cut }} \times t_{\text {load }}\right)}{\left[\left(P_{\text {CNC }}+P_{\text {hydraulic }}\right) \times\left(t_{\text {start }}+t_{\text {standby }}\right)+\sum_{k=0}^{m} \xi(k) P_{k} t_{k}+\left(\omega n+\tilde{\xi}_{f}+C\right) \frac{L_{n o-l o a d}}{v_{f}}+\left(\omega n+\xi_{f}+C+1.2 P_{\text {cut }}\right) \frac{M R V}{M R R}\right]}
$$

\subsection{Carbon Efficiency Model}

The traditional emission conservation is mainly focused on the reduction of carbon emission but in the actual machining process, the parts and materials are removed by processing action, that is, the carbon emission from the cut-volume is truly utilized during the manufacturing process. Therefore, the relationship between the produced carbon emissions per unit cut-volume should be taken into account when considering low-carbon manufacturing. In our previous work [18], the concept of carbon 
efficiency was proposed, which could be calculated in Equation (14) And the flow chart of carbon efficiency is shown in Figure 3.

$$
Q=\frac{C_{i}}{\Delta V}
$$

where $Q$ is the carbon efficiency, $C_{i}$ is the total carbon emission in machining process, $\Delta V$ is the material removal volume in machining process.

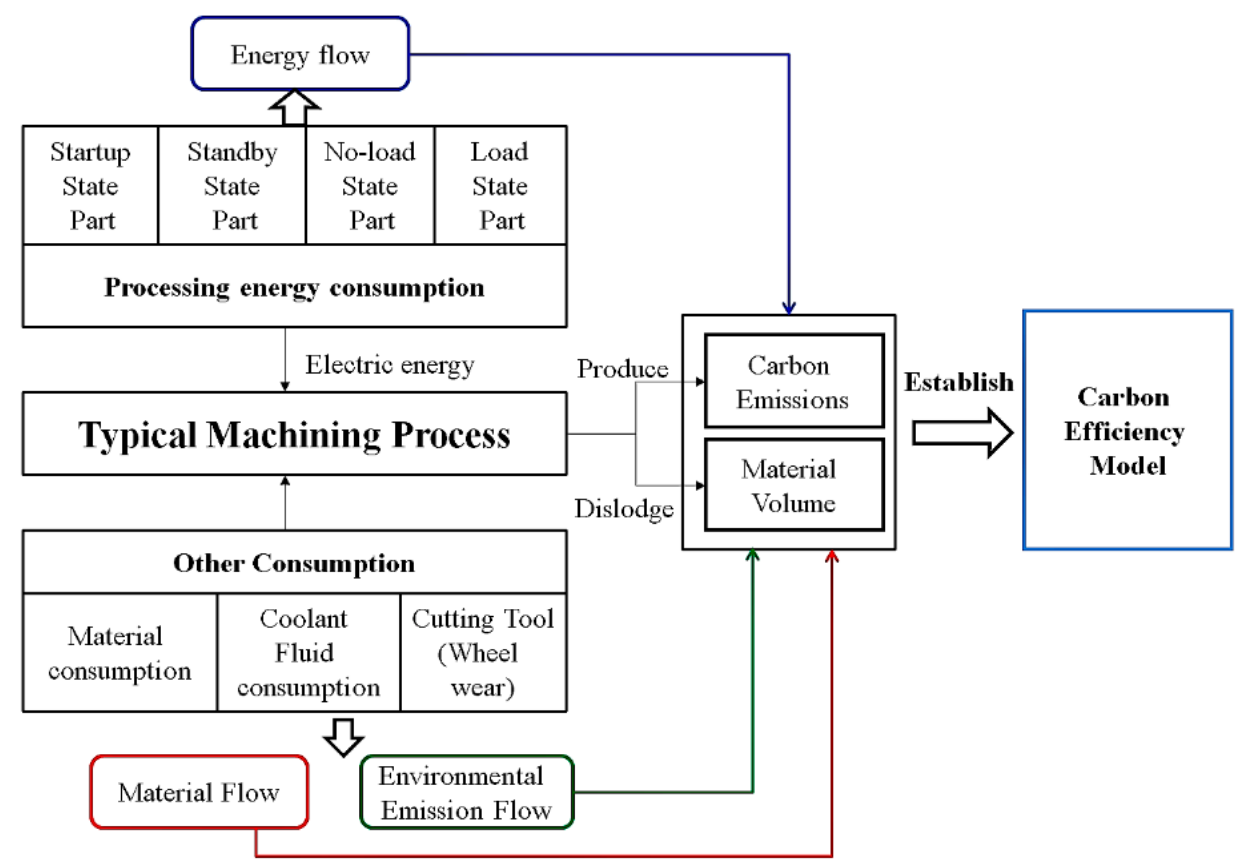

Figure 3. Carbon efficiency model.

The total carbon emission from machine tool machining process are direct and indirect emissions from the consumption of energy and materials, mainly including the carbon emission from electric energy $C_{e}$, carbon emission from material consumption $C_{m}$ and carbon emission from cutting process (carbon emission from cutting tool/grinding wheel consumption $C_{t}$ and carbon emission from coolant liquid consumption $C_{f}$ ) [34].

\subsubsection{Carbon Emissions from Electric Energy Consumption}

Carbon emissions in machining process is mostly from electric energy consumption, during the machining process, the machine consumes the input electrical energy for material removal. The carbon footprint can be expressed as the equivalent mass of the generated greenhouse gas converted to carbon dioxide per $1 \mathrm{~kW} \cdot \mathrm{h}$ of electricity generated, in units of $\mathrm{kg} \mathrm{CO} / \mathrm{kW} \cdot \mathrm{h}$. And the consumed energy can be calculated as shown in Equation (15). The calculation method of electric energy was discussed in detail in Section 2.1.

$$
C_{e}=E_{\text {process }} \times f_{e}
$$

where $f_{e}$ is the carbon emission factor of electricity, which is closely related to the composition of the power grid.

\subsubsection{Carbon Emissions from Material Consumption}

The machining system actually needs to cut off excess material according to the process requirements and the part of the material that enters the product will follow the product to the 
next step. Therefore, carbon emissions from material consumption mainly considers the carbon emission from material removal and treatment of waste material, as shown in Equation (16).

$$
C_{m}=\Delta m \times\left(f_{m 1}+f_{m 2}\right)
$$

where $f_{m 1}, f_{m 2}$ are the carbon emission factor of raw material preparation and waste material treatment.

\subsubsection{Carbon Emissions from Coolant Liquid Consumption}

In the machining process, coolant liquid will return to the box after used and evaporate or stick on the workpiece/wear debris. Therefore, for the special machining process, the carbon emission from coolant liquid consumption should be converted by replacement cycle time standard. The calculation formula is as the following Equation (17).

$$
C_{l}=\frac{T_{m}}{T_{c}} \rho_{c} V_{f} \times\left(f_{l 1}+f_{l 2}\right)
$$

where $T_{m}$ is the processing time, $T_{c}$ is the replacement cycle time of cooling fluid, $\rho_{c}$ is the density of cooling fluid, $V_{f}$ is the replaced volume of cooling fluid, $f_{l 1}, f_{l 2}$ are the carbon emission factor of cooling fluid and waste liquid treatment.

\subsubsection{Carbon Emissions from Cutting Tools (Grinding Wheel) Consumption}

Generally speaking, the direct environmental impact caused by the cutting tools (grinding wheel) is relatively small during the machining process, mainly the caused by the indirect influence (the environmental impact of the tool preparation process has been assessed in the tool use process). Thus, for a certain process, the carbon emission of cutting tool (grinding wheel) is calculated in a similar way to that of the coolant fluid, which also employs a conversion distribution method according to time.

$$
C_{t}=\frac{T_{m}}{T_{T}} m_{T} \times f_{t}
$$

where $T_{T}$ is the tool life (grinding wheel), $m_{T}$ is the quality of cutting tool (grinding wheel), $f_{t}$ is carbon emission factor of cutting tool (grinding wheel).

Based on Equation (13) and synthesizing the Equations (14)-(18), carbon efficiency model can be established as the following Equation (19).

$$
Q=\frac{C_{i}}{\Delta V}=\left(C_{e}+C_{m}+C_{s}+C_{f}\right) / \frac{\Delta m}{\rho}=\left\{\left[\begin{array}{c}
\left(P_{C N C}+P_{\text {hydraulic }}\right) \times\left(t_{\text {start }}+t_{s t a n d b y}\right)+\sum_{k=0}^{m} \xi(k) P_{k} t_{k} \\
+\left(\omega n+\xi v_{f}+C\right) \frac{L_{n o-l o a d}}{v_{f}}+\left(\omega n+\xi v_{f}+C+1.2 P_{c u t}\right) \frac{M R V}{M R R} \\
\Delta m \times\left(f_{m 1}+f_{m 2}\right)+\frac{T_{m}}{T_{c}} \rho_{c} V_{f} \times\left(f_{l 1}+f_{l 2}\right)+\frac{T_{m}}{T_{T}} m_{T} \times f_{t}
\end{array}\right] \times f_{e}+\right\} / \frac{\Delta m}{\rho}
$$

where $\Delta m$ is the mass difference value before and after processing, $\rho$ is the density of parts. The relevant carbon emission factors can be obtained through the literatures [35-37].

\subsection{Green Degree Model}

The machine tools not only consume a lot of limited resources but also pollute the environment in the production process. With the continuous expansion of the application range of machine tools, it is of great significance to evaluate the green level of machine tool and machining process, to minimize its impact on the environment resources and meet the requirements of sustainable development. Green degree is an important indicator for the green evaluation of products, which can quantify the greenness of the product to the environment $[38,39]$.

The green degree of typical machine tools can be defined as establishing a reasonable evaluation system for resource attribute, environment attribute, human health and precision efficiency in the production process, which can be used to judge the green level of process and put forward 
corresponding improvement suggestions. According to the machining process, green degree evaluation system model is established from four aspects: resource attribute index, environment attribute index, human health index and precision efficiency index. The formula is as follows:

$$
A=\tilde{W}_{i} \times R_{i}=\left(a_{1}, a_{2}, \ldots, a_{m}\right)
$$

where $\tilde{W}_{i}$ is the weight vector of the index $i$ relative to the total target, $R_{i}$ is the membership matrix of each evaluation index, $A$ is the evaluation result of each evaluation index relative to the overall target. The process green evaluation system is shown in Figure 4.

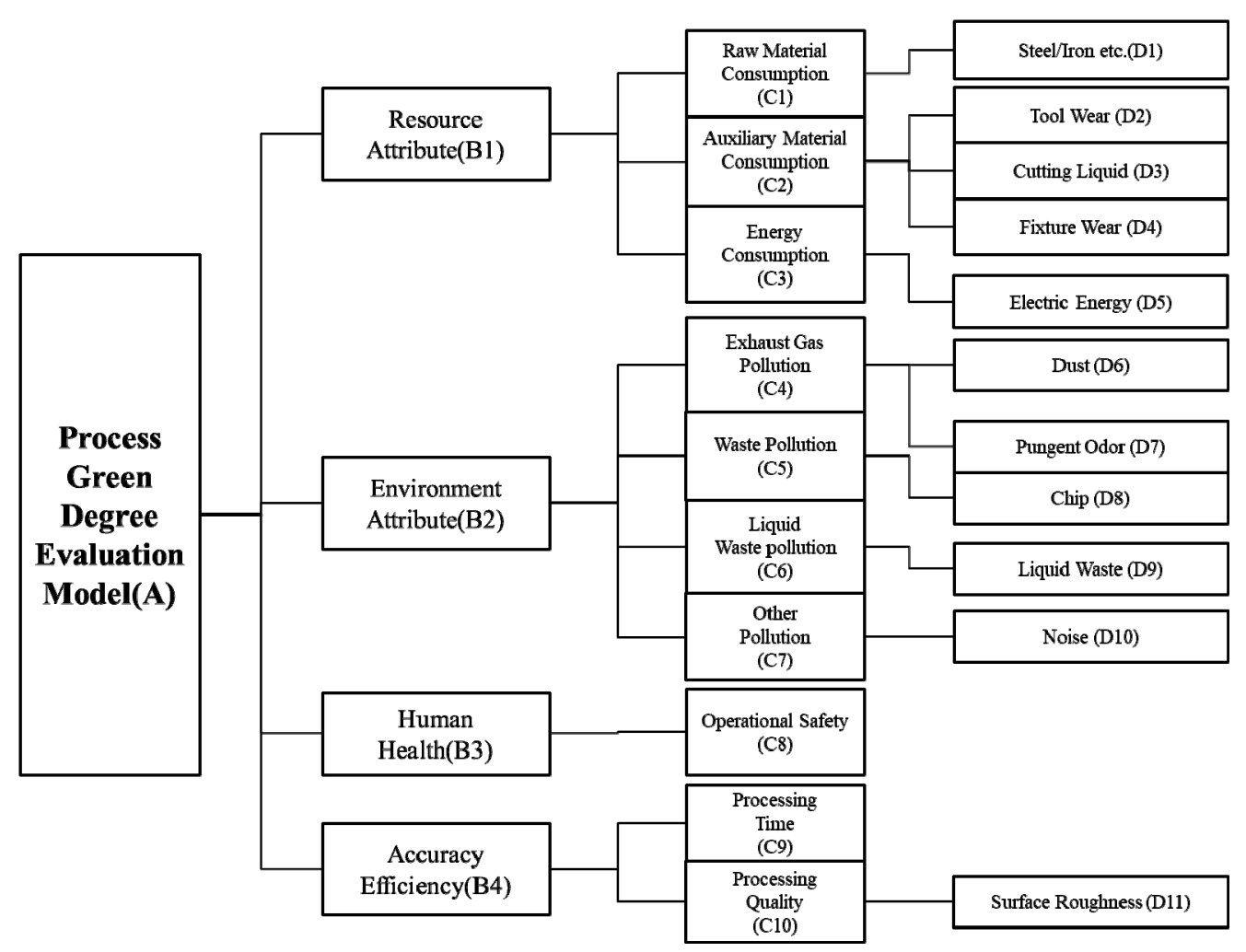

Figure 4. Process green degree evaluation model.

\subsubsection{Evaluation Index Weight Determination}

The steps to determine the weight of evaluation index are as follows [40]:

1. Construct the priority relationship judgment matrix

The priority relationship judgment matrix (Fuzzy complementary matrix) $\left(R_{i j}\right)_{n \times n}$. The 0.1-0.9 fuzzy scale method [41] is used in this paper to definite the quantitative scale in order to quantitatively describe the importance of each index under the same target.

2. Construct the fuzzy uniform matrix

Transform the fuzzy complementary matrix into the fuzzy congruence matrix, that is, the fuzzy complementary matrix is first summed in rows $r_{i}=\sum_{k=1}^{n} f_{i k}, i=1,2 \cdots \cdots, n$ and then the row changes are as follows:

$$
r_{i j}=\frac{r_{i}-r_{j}}{2 n}+0.5
$$


3. Determine the weight of each index

Determine the weight of each index by square root method according to the relation between fuzzy consistent matrix elements and weight. Each row of the fuzzy consistent matrix is changed as follows:

$$
S_{i}\left(\prod_{j=1}^{n} r_{i j}\right)^{\frac{1}{n}}
$$

\section{Fuzzy matrix normalization}

According $\overline{S_{i}}=\frac{S_{i}}{\sum_{j=1}^{n} S_{i}}$ and then the weight vector of the corresponding matrix index is obtained $S_{i}=\left(\overline{S_{1}}, \overline{S_{2}}, \cdots \overline{S_{n k}}\right)$.

Where $S_{n k}$ is the weight vector of the $n$ index in the $k$ layer relative to an index in the upper layer. If the weight vector of the indicators in the $k-1$ layer to the total target is calculated as $W^{k-1}=\left(W_{1}^{k-1}, W_{2}^{k-1}, \cdots, W_{n_{k-1}}^{k-1}\right)^{T}$, then the composite vector $W^{k}$ of the indicators in the $k$ layer to the total target is given by the following equation.

$$
W^{k}=\left(W_{1}^{k}, W_{2}^{k}, \cdots W_{n_{k}}^{k}\right)^{T}=S_{k} W^{k-1}
$$

And in general, $W^{k}=S^{k} S^{k-1} \cdots S^{3} W^{2}, W^{2}$ is going to be a single term vector.

5. Determine the expert weight coefficient.

The expert weight coefficient includes subjective weight coefficient and objective weight coefficient. Expert weight coefficient: $\beta_{t}=\alpha M_{t}+(1-\alpha) U_{k}$, where $\alpha$ is the degree of preference coefficient of subjective and objective weight. To show that subjective and objective are equally important, Take $\alpha=0.5$.

Subjective weight coefficient: Suppose there are $s$ experts, the calculation expression of the $t$ expert weight coefficient is:

$$
G_{t}=a_{t} \times b_{t} \times c_{t} \times d_{t} \times e_{t} \times f_{t}
$$

where $a_{t}, b_{t}, c_{t}, d_{t}, e_{t}, f_{t}$ are experts' familiarity, expertise and experience, judgment basis, confidence, industry background and reputation. Then normalization the subjective weight coefficient $M_{t}=$ $G_{t} / \sum_{t=1}^{s} G_{t}$.

Objective weight coefficient: $s$ evaluation experts evaluate the $n$ evaluation objects as the weight value ranking vector $W^{k}=\left(W_{1}^{k}, W_{2}^{k}, \cdots W_{n}^{k}\right)^{T}$. The distance between $W^{(p)}$ and $W^{(q)}(p, q=1,2, \cdots s)$ can be defined as:

$$
d_{p q}=d\left(W^{(p)}, W^{(q)}\right)=\left[\frac{1}{2} \sum_{j=1}^{n}\left(W_{j}^{(p)}-W_{j}^{(q)}\right)^{2}\right]^{\frac{1}{2}}
$$

As we known, $0 \leq d\left(W^{(P)}, W^{(q)}\right) \leq 1$, the smaller $d\left(W^{(p)}, W^{(q)}\right)$ is, the closer $W^{(p)}$ is to $W^{(q)}$. The distance matrix is constructed as follows:

$$
d=\left(d_{i j}\right)_{s \times s}=\left[\begin{array}{cccc}
0 & d_{12} & \cdots & d_{1 s} \\
d_{21} & 0 & \cdots & d_{2 s} \\
\vdots & \vdots & 0 & \vdots \\
d_{s 1} & d_{s 2} & \cdots & 0
\end{array}\right]
$$


where $d$ is a symmetric matrix. Define $d_{k}=\sum_{l=1}^{s} d_{k l}(k=1,2 \cdots, s), d_{k}$ reflects how close $W^{(k)}$ is to other ordering vectors. The smaller $d_{k}$ is, the closer it is to other vectors. Therefore, $U_{k}=\left(1 / d_{k}\right) / \sum_{k=1}^{s}\left(1 / d_{k}\right), k=$ $1,2, \cdots s$ can be used as the objective weight of the evaluator.

\subsubsection{Evaluation Membership Matrix Determination}

1. Establish the evaluation index

$U=\left\{\mathbf{u}_{1}, u_{2}, \cdots, \mathbf{u}_{i}, \cdots, u_{m}\right\}$, where $m$ is the number of evaluation aspects. Then, it is divided down successively and the $i$ th aspect is further divided into the following equation:

$$
u_{i}=\left\{u_{1}, u_{2}, \cdots, u_{j}, \cdots, u_{n}\right\}_{i}
$$

where $n$ is the number of evaluation elements in the $i$ th evaluation area. Then the $j$ th element $u_{i j}(j=$ $1,2, \cdots, n)$ is divided, which is divided into: $u_{i j}\left(u_{1}, u_{2}, \cdots, u_{k}, \cdots, u_{p}\right)_{i j}$, where $p$ is the number of evaluation indicators in the $i$ th evaluation aspect and the $j$ th evaluation element.

2. Determine the evaluation

Set $V=\left\{\mathrm{v}_{1}, v_{2}, \cdots, v_{q}\right\}$, each evaluation index can be simply evaluated by taking the same number of evaluation grade sets. where $q$ is the number of evaluation grades.

3. Determine the membership matrix of evaluation.

If a single index is evaluated for evaluation factors, then the single index evaluation matrix is $R_{i}=\left(r_{i j, p}\right)_{n_{i} \times m}$. Where $\left(r_{i j, p}\right)$ is the membership degree of index $x_{i j}$ to comment $y_{k}, y_{k}$ represents the number of evaluation aspects and $n_{i}$ represents the number of evaluation elements in the $i$ th evaluation aspect. The evaluation level rules are formulated by experts through the actual processing technology and related standards of on-site production. Finally, its quantitative score is taken as the corresponding membership matrix element.

\section{Results}

\subsection{Experimental Setup}

Five different kind of typical machine tools were selected to study the green characteristics (energy efficiency, carbon efficiency and green degree) of different machines. The machine tools used in this paper including one lathe (CA6140 common lathe, Shengyang Machine Tool Group Co., Ltd, Shengyang, China), one milling machine (X62W universal knee-type milling machine, Shengyang Machine Tool Group Co., Ltd., Shengyang, China), one planer (BM2015 gantry planer, Shangdong Yasheng Heavy Shares Co., Ltd., Gaomi, China), one grinder (MGK7120 CNC surface grinder, Hangzhou Machine Tool Group Co., Ltd., Hangzhou, China) and one drilling machine (Z3063 radial drilling machine, Dalian NO.2 Machine Tool Co., Ltd., Dalian, China). All these machine tools are manufactured in China. For machining test, head frame spindle (cutting and grinding) and head frame box (milling, planing and drilling) were selected as the test workpieces because of its wide use in manufacturing industry.

During each test, the total energy consumption was measured using AWS2013S Power Analyzer digital power meter (AITEK, Taiwan, China). Roughness of each machining surface are acquired and sampled by using surface roughness comparing sample piece (The grinding process is measured using MarSurf M300 surface roughness meter, Mahr, Esslingen, Germany, due to the precision machining requires high roughness). The noise and dust of each process were recorded by using noise tester (TES, Taiwan, China) and dust tester (Da sen, Qingdao, China). The experimental equipment, experimental workpieces and measuring instruments are collected in factories and laboratories, as shown in Figure 5. 

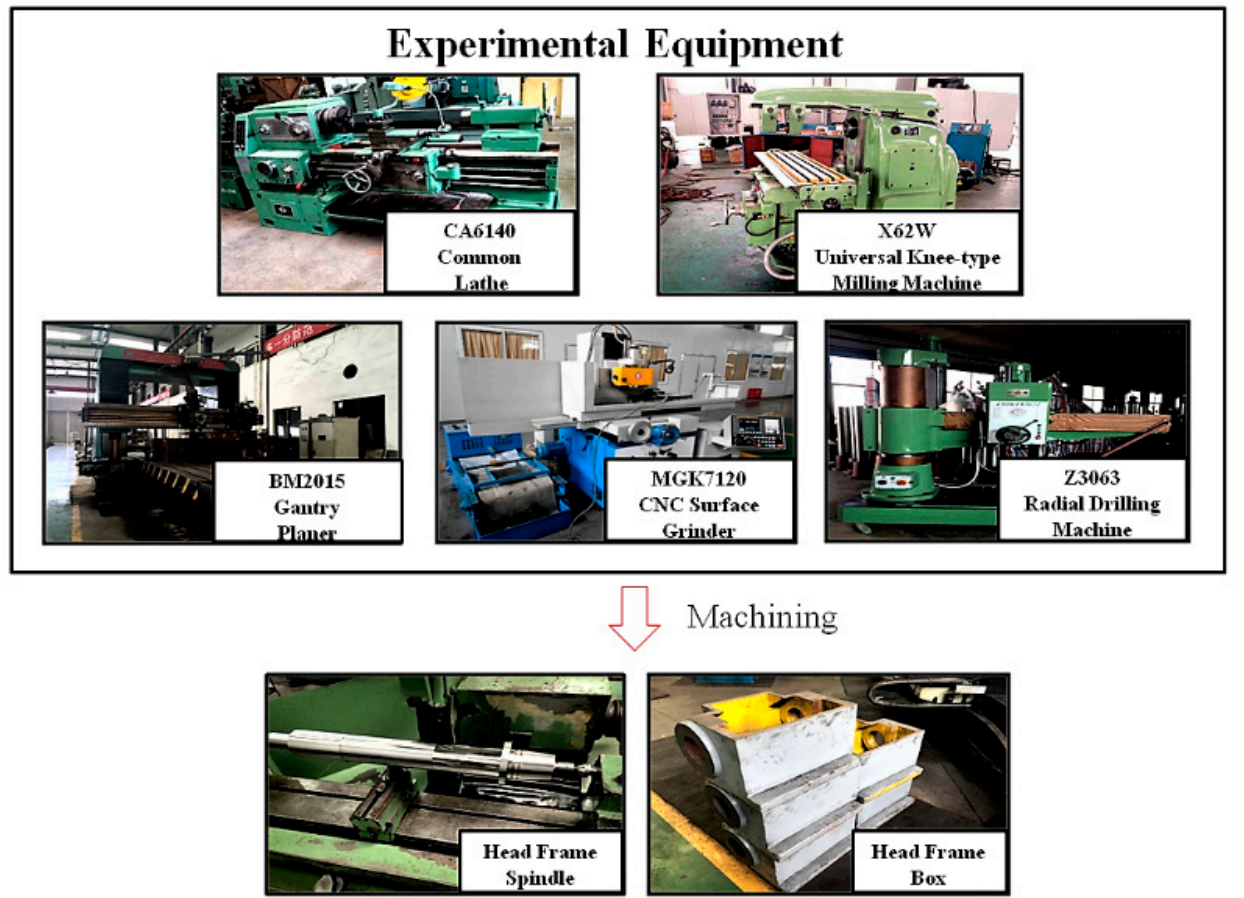

Energy Consumption Roughness

\section{Noise}

Dust

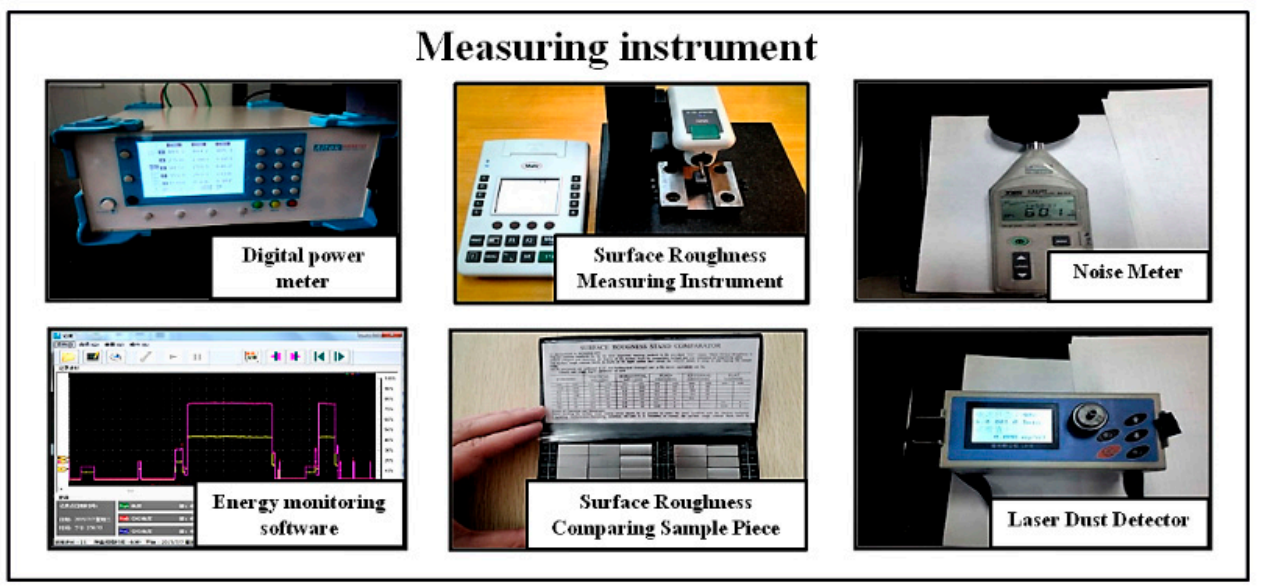

Figure 5. Experimental equipment, experimental workpieces and measuring instruments.

Orthogonal experimental design, a design method for studying multi-factor and multi-level, which is a high-efficiency, fast and economical experimental design method based on orthogonality to select some representative points from comprehensive experiments. The experimental test bench, the same experimental materials and tools designed above are selected. Considering the machining characteristics of each machine tool, the processing parameters of the 3 factors commonly used in each process are selected and each processing parameters have 5 levels. Then Statistical Product and Service Solutions (SPSS) software (19.0, SPSS, Chicago, IL, USA, 2011) is used to design $\mathrm{L}_{16}\left(4^{3}\right)$ orthogonal experiment, as shown in Table 1. 
Table 1. Factor level table.

\begin{tabular}{|c|c|c|c|c|}
\hline \multirow{2}{*}{$\begin{array}{l}\text { Machining } \\
\text { Process }\end{array}$} & \multirow{2}{*}{ Level } & \multicolumn{3}{|c|}{ Related Parameters } \\
\hline & & A & B & $\mathrm{C}$ \\
\hline & & $\begin{array}{l}\text { Spindle speed } \\
\text { (r/min) }\end{array}$ & Feed $(\mathrm{mm} / \mathrm{r})$ & $\begin{array}{l}\text { Cutting depth } \\
(\mathrm{mm})\end{array}$ \\
\hline \multirow{5}{*}{ Turning } & 1 & 160 & 0.1 & 0.5 \\
\hline & 2 & 250 & 0.2 & 1 \\
\hline & 3 & 320 & 0.3 & 1.5 \\
\hline & 4 & 450 & 0.4 & 2 \\
\hline & & $\begin{array}{l}\text { Spindle speed } \\
\text { (r/min) }\end{array}$ & $\begin{array}{l}\text { Feed Rate } \\
(\mathrm{mm} / \mathrm{min})\end{array}$ & $\begin{array}{l}\text { Milling depth } \\
(\mathrm{mm})\end{array}$ \\
\hline \multirow{5}{*}{ Milling } & 1 & 190 & 75 & 2 \\
\hline & 2 & 235 & 95 & 3 \\
\hline & 3 & 300 & 118 & 4 \\
\hline & 4 & 375 & 150 & 5 \\
\hline & & $\begin{array}{l}\text { Spindle speed } \\
\text { (r/min) }\end{array}$ & Feed $(\mathrm{mm} / \mathrm{r})$ & $\begin{array}{l}\text { Planning depth } \\
\qquad(\mathrm{mm})\end{array}$ \\
\hline \multirow{5}{*}{ Planning } & 1 & 1200 & 0.3 & 3 \\
\hline & 2 & 1500 & 0.4 & 4 \\
\hline & 3 & 1800 & 0.5 & 5 \\
\hline & 4 & 2100 & 0.6 & 6 \\
\hline & & $\begin{array}{l}\text { Spindle speed } \\
(\mathrm{r} / \mathrm{min})\end{array}$ & $\begin{array}{l}\text { Feed Rate } \\
(\mathrm{mm} / \mathrm{min})\end{array}$ & $\begin{array}{l}\text { Grinding depth } \\
(\mathrm{mm})\end{array}$ \\
\hline \multirow{5}{*}{ Grinding } & 1 & 2100 & 1000 & 0.01 \\
\hline & 2 & 2400 & 2000 & 0.02 \\
\hline & 3 & 2700 & 3000 & 0.03 \\
\hline & 4 & 3000 & 4000 & 0.04 \\
\hline & & $\begin{array}{l}\text { Spindle speed } \\
\text { (r/min) }\end{array}$ & Feed $(\mathrm{mm} / \mathrm{r})$ & $\begin{array}{c}\text { Drilling } \\
\text { diameter }(\mathrm{mm})\end{array}$ \\
\hline \multirow{4}{*}{ Drilling } & 1 & 200 & 0.06 & 6 \\
\hline & 2 & 250 & 0.1 & 8 \\
\hline & 3 & 320 & 0.13 & 10 \\
\hline & 4 & 400 & 0.16 & 12 \\
\hline
\end{tabular}

\subsection{Regression Analysis of Power Models}

The startup state and standby state power are mainly determined by the structure of the machine tool itself, almost a constant. Therefore, the experimental results of the no-load power and the material removal power are selected after the data processing according to the orthogonal experimental table, these data are all collected from digital power meter. According to the above experimental data, Matrix Laboratory (MATLAB) software (2012a, MathWorks, Natick, MA, USA, 2012) is used to carry out data regression fitting and the no-load power and material removal power prediction model are obtained. Take the test number 1 of turning process as an example, the calculation process is as follows: (1) predicted no-load power $=5048.4+0.7 \times 160+0.1 \times 103.5=5170.75 \mathrm{~W}$. (2) predicted material removal power $=4.7421 \times 160^{0.705} \times 0.1^{0.7469} \times 1^{0.3589}=30.47 \mathrm{~W}$. (since the rest of the content is similar, it is not presented here).

The experimental power values are then compared with the predicted power values related to the processing parameters (no-load power and material removal power) and partial results are shown in Table 2. 
Table 2. Comparison of experimental result and predicted result.

\begin{tabular}{|c|c|c|c|c|c|c|c|c|c|c|}
\hline $\begin{array}{l}\text { Machining } \\
\text { Process }\end{array}$ & $\begin{array}{c}\text { Test } \\
\text { Number }\end{array}$ & A & B & C & $\begin{array}{c}\text { No-Load } \\
\text { Power } \\
\text { (W) }\end{array}$ & $\begin{array}{c}\text { Predicted } \\
\text { No-Load } \\
\text { Power }(W)\end{array}$ & $\begin{array}{c}\text { Error } \\
(\%)\end{array}$ & $\begin{array}{c}\text { Material } \\
\text { Removal } \\
\text { Power (W) }\end{array}$ & $\begin{array}{c}\text { Predicted } \\
\text { Material } \\
\text { Removal } \\
\text { Power (W) }\end{array}$ & $\begin{array}{c}\text { Error } \\
(\%)\end{array}$ \\
\hline \multirow{6}{*}{ Turning } & 1 & 160 & 0.1 & 1 & 5180 & 5170 & 0.19 & 29 & 30 & 4.85 \\
\hline & 2 & 160 & 0.2 & 1.5 & 5193 & 5180 & 0.24 & 54 & 59 & 9.30 \\
\hline & 8 & 250 & 0.4 & 1 & 5251 & $\ldots 264$ & 0.26 & 116 & 117 & 1.12 \\
\hline & 9 & 320 & 0.1 & 1.5 & 5340 & 5282 & 1.08 & 58 & 57 & 1.15 \\
\hline & 15 & 450 & 0.3 & 1 & 5398 & $\begin{array}{c}\cdots \cdots \\
5394\end{array}$ & 0.07 & 133 & 143 & 7.67 \\
\hline & 16 & 450 & 0.4 & 1.5 & 5414 & 5404 & 0.18 & 207 & 205 & 0.80 \\
\hline \multirow{6}{*}{ Milling } & 1 & 190 & 75 & 3 & 5575 & 5584 & 0.15 & 46.5 & 43 & 7.49 \\
\hline & 2 & 190 & 95 & 4 & 5622 & 5588 & 0.61 & 69 & 69 & 0.52 \\
\hline & 8 & 300 & 75 & 4 & 5642 & $\begin{array}{c}\ldots . . \\
5628\end{array}$ & 0.26 & 53 & 55 & 3.96 \\
\hline & 9 & 300 & 95 & 3 & 5609 & 5632 & 0.40 & 50 & 55 & 10.89 \\
\hline & 15 & 375 & 118 & 3 & 5643 & 5666 & 0.41 & 73.7 & 70 & 5.53 \\
\hline & 16 & 375 & 150 & 4 & 5674 & 5673 & 0.02 & 123 & 113 & 8.40 \\
\hline \multirow{6}{*}{ Planning } & 1 & 1200 & 0.3 & 4 & 4356 & 4301 & 1.25 & 1313 & 1303 & 0.74 \\
\hline & 2 & 1200 & 0.4 & 5 & 4458 & 4444 & 0.33 & 1730 & 1782 & 3.03 \\
\hline & 8 & 1500 & 0.6 & 4 & 5181 & $\begin{array}{c}\ldots \ldots \\
5208\end{array}$ & 0.51 & 2099 & 2147 & 2.27 \\
\hline & 9 & 1800 & 0.3 & 5 & 5120 & 5261 & 2.76 & 1555 & 1602 & 3.02 \\
\hline & 15 & 2100 & 0.5 & 4 & 6206 & $\begin{array}{c}\ldots . . \\
6026\end{array}$ & 2.91 & 2120 & 2039 & 3.84 \\
\hline & 16 & 2100 & 0.6 & 5 & 6178 & 6168 & 0.17 & 2502 & 2602 & 4.01 \\
\hline \multirow{6}{*}{ Grinding } & 1 & 2100 & 1000 & 0.01 & 5699 & 5776 & 1.35 & 162 & 165 & 1.8 \\
\hline & 2 & 2100 & 2000 & 0.02 & 5763 & 5806 & 0.75 & 408 & 456 & 11.79 \\
\hline & 8 & 2400 & 4000 & 0.03 & 5774 & 5927 & 2.65 & 1030 & 1024 & 0.62 \\
\hline & 9 & 2700 & 1000 & 0.03 & 5812 & 5896 & 1.44 & 459 & 482 & 5.12 \\
\hline & 15 & 3000 & 3000 & 0.02 & 5814 & $\begin{array}{c}\ldots . . . \\
6017\end{array}$ & 3.49 & 650 & 655 & 0.74 \\
\hline & 16 & 3000 & 4000 & 0.01 & 5989 & 6047 & 0.97 & 408 & 415 & 1.83 \\
\hline \multirow{6}{*}{ Drilling } & 1 & 200 & 0.06 & 8 & 4196 & 4209 & 0.3 & 20.3 & 18.3 & 10.04 \\
\hline & 2 & 200 & 0.1 & 10 & 4211 & 4238 & 0.65 & 30.2 & 28.9 & 4.42 \\
\hline & 8 & 250 & 0.16 & 8 & 4297 & 4308 & 0.24 & 35.9 & 36.8 & 2.51 \\
\hline & 9 & 320 & 0.06 & 10 & 4280 & 4269 & 0.27 & 32.4 & 32.3 & 0.22 \\
\hline & 15 & 400 & 0.13 & 8 & 4308 & 4360 & 1.22 & 46.6 & 48.4 & 3.83 \\
\hline & 16 & 400 & 0.16 & 10 & 4388 & 4383 & 0.13 & 67 & 65.1 & 2.76 \\
\hline
\end{tabular}

According to the above experimental data, the no-load power model and the material removal power model of these experimental machine tools can be expressed as:

$$
\begin{gathered}
\left\{\begin{array}{c}
P_{u}^{C A 6140}=5048.4+0.7 n+103.5 f\left(R^{2}=0.8881\right) \\
P_{c}^{C A 6140}=4.7421 n^{0.705} f^{0.7469} a_{p}{ }^{0.3589}\left(R^{2}=0.9808\right) \\
P_{u}^{X 62 W}=5492.6+0.4 n+0.2 v_{w}\left(R^{2}=09021\right) \\
P_{c}^{X 62 W}=0.1838 n^{0.0259} v_{w}{ }^{1.0236} a_{p}{ }^{0.8194}\left(R^{2}=0.9446\right) \\
P_{u}^{B M 2015}=1955.3+1.6 n+1420.5 f\left(R^{2}=0.8925\right) \\
P_{c}^{B M 2015}=316.7401 n^{0.2015} f^{0.6551} a_{p}{ }^{0.5587}\left(R^{2}=0.9457\right) \\
P_{u}^{M G K 7120}=5325.2+0.2 n+0.0305 v_{w}\left(R^{2}=0.8715\right) \\
P_{c}^{M G K 7120}=12.1061 n^{0.3621} v_{w}^{0.5733} a_{p}^{0.8943}\left(R^{2}=0.9887\right) \\
P_{u}^{Z 3063}=4064.3+0.5 n+738.8 f\left(R^{2}=0.8442\right) \\
P_{c}^{Z 3063}=21.7447 n^{0.3621} f^{0.5733} d^{0.8943}\left(R^{2}=0.9857\right)
\end{array}\right.
\end{gathered}
$$


After the respective statistical tests, we mainly focused on the statistical problems about the indicators of regression linear accuracy (R-sq and $R^{2}$ adjust), as shown in Equation (28). $R$-sq is the percentage of variation in the response interpreted by the model, in general, the higher the R-sq value, the higher the goodness of the model fit data. The fitting values of no-load power and material removal power at all stage indicators of regression linear accuracy ( $R$-sq and $\mathrm{R}^{2}$ adjust) are $>0.8$, which indicates the linear power fitting model has good fitting degree. It can be seen from Table 2 that the actual value of the no-load power and the actual value of the material removal power are within $5 \%$ of the predicted value.

It demonstrates the feasible and high precision of the proposed models, which can well describe the no-load power and the material removal power under different technological parameters. Through the established power model, combining with the other resource consumption, the energy efficiency model and carbon efficiency model can be obtained by the formula. Meanwhile, the corresponding energy efficiency and carbon efficiency can be calculated according to the specific machining process.

\subsection{Determination of Green Degree Evaluation Index and Weight}

According to the machining process green evaluation system model established in Section 2.3, the upper-level indicators have an inclusion relationship with the lower-level indicators. The lower-level indicators differ from the upper-level indicators in the importance of different indicators. In this paper, 0.1-0.9 scale method is used to compare the relative importance of each index, as shown in Table 3 and obtain the priority relationship judgment matrix of each index.

Table 3. Fuzzy scale and method.

\begin{tabular}{cc}
\hline Fuzzy Scale & Explanation \\
\hline 0.1 & The latter is extremely important than the former compared to the two elements \\
0.2 & The latter is strongly important than the former compared to the two elements \\
0.3 & The latter is obviously important than the former compared to the two elements \\
0.4 & The latter is slightly important than the former compared to the two elements \\
0.5 & Both are equally important compared to the two elements \\
0.6 & The former is extremely important than the latter compared to the two elements \\
0.7 & The former is strongly important than the latter compared to the two elements \\
0.8 & The former is obviously important than the latter compared to the two elements \\
0.9 & The former is slightly important than the latter compared to the two elements \\
\hline
\end{tabular}

The two expert groups used the 0.1-0.9 scale method to compare the indicators in pairs. By comparing the relative importance between the two elements, the priority judgment matrix of each indicator is obtained. The priority relationship judgment matrix is shown in Tables 4-9.

Table 4. Layer judgment matrix (A-B).

\begin{tabular}{ccccc}
\hline General Attribute (A-B) & $\begin{array}{c}\text { Resource } \\
\text { Attribute B1 }\end{array}$ & $\begin{array}{c}\text { Environment } \\
\text { Attribute B2 }\end{array}$ & $\begin{array}{c}\text { Human } \\
\text { Health B3 }\end{array}$ & $\begin{array}{c}\text { Accuracy } \\
\text { Efficiency B4 }\end{array}$ \\
\hline Resource attribute B1 & 0.5 & 0.2 & 0.1 & 0.1 \\
Environment attribute B2 & 0.8 & 0.5 & 0.2 & 0.2 \\
Human health B3 & 0.9 & 0.8 & 0.5 & 0.2 \\
Accuracy efficiency B4 & 0.9 & 0.8 & 0.8 & 0.5 \\
\hline
\end{tabular}

Table 5. Layer judgment matrix (B1-C).

\begin{tabular}{cccc}
\hline Resource Attribute (B1-C) & $\begin{array}{c}\text { Raw Material } \\
\text { Consumption C1 }\end{array}$ & $\begin{array}{c}\text { Auxiliary Material } \\
\text { Consumption C2 }\end{array}$ & $\begin{array}{c}\text { Energy } \\
\text { Consumption C3 }\end{array}$ \\
\hline Raw material consumption C1 & 0.5 & 0.3 & 0.8 \\
Auxiliary material consumption C2 & 0.7 & 0.5 & 0.9 \\
Energy consumption C3 & 0.2 & 0.1 & 0.5 \\
\hline
\end{tabular}


Table 6. Layer judgment matrix (B2-C).

\begin{tabular}{ccccc}
\hline $\begin{array}{c}\text { Environment Attribute } \\
\text { (B2-C) }\end{array}$ & $\begin{array}{c}\text { Exhaust Gas } \\
\text { Pollution C4 }\end{array}$ & $\begin{array}{c}\text { Waste } \\
\text { Pollution C5 }\end{array}$ & $\begin{array}{c}\text { Liquid Waste } \\
\text { Pollution C6 }\end{array}$ & $\begin{array}{c}\text { Other Pollution } \\
\text { C7 }\end{array}$ \\
\hline Exhaust gas pollution C4 & 0.5 & 0.7 & 0.6 & 0.7 \\
Waste pollution C5 & 0.3 & 0.5 & 0.4 & 0.6 \\
Liquid waste pollution C6 & 0.4 & 0.6 & 0.5 & 0.7 \\
Other pollution C7 & 0.3 & 0.4 & 0.3 & 0.5 \\
\hline
\end{tabular}

Table 7. Layer judgment matrix (B4-C).

\begin{tabular}{ccc}
\hline Accuracy Efficiency (B4-C) & Processing Time C9 & Processing Quality C10 \\
\hline Processing time C9 & 0.5 & 0.3 \\
Processing quality C10 & 0.7 & 0.5 \\
\hline
\end{tabular}

Table 8. Layer judgment matrix (C2-D).

\begin{tabular}{cccc}
\hline $\begin{array}{c}\text { Auxiliary Material } \\
\text { Consumption (C2-D) }\end{array}$ & Tool Wear D2 & Cutting Liquid D3 & Fixture Wear D4 \\
\hline Tool wear D2 & 0.5 & 0.7 & 0.2 \\
Cutting liquid D3 & 0.3 & 0.5 & 0.4 \\
Fixture wear D4 & 0.8 & 0.6 & 0.5 \\
\hline
\end{tabular}

Table 9. Layer judgment matrix (C4-D).

\begin{tabular}{ccc}
\hline Exhaust Gas Pollution (C4-D) & Dust D6 & Pungent Odor D7 \\
\hline Dust D6 & 0.5 & 0.7 \\
Pungent odor D7 & 0.3 & 0.5 \\
\hline
\end{tabular}

According the Equations (20)-(26), the fuzzy uniform matrix was constructed and the corresponding index matrix weights were obtained by the related changes of the fuzzy uniform matrix. The matching index weights of different levels are as follows:

$$
\left\{\begin{array}{c}
W_{A-B}=(0.3216,0.2698,0.1845,0.2241) \\
W_{B 1-C}=(0.333,0.241,0.426) \\
W_{B 2-C}=(0.2185,0.2626,0.2374,0.2815) \\
W_{B 4-C}=(0.45,0.55) \\
W_{C 2-D}=(0.3898,0.3221,0.2881) \\
W_{C 4-D}=(0.55,0.45)
\end{array}\right.
$$

The expert weight coefficient $\beta_{t}=(0.26,0.04,0.04,0.013,0.052,0.26,0.175,0.06,0.08,0.02)$ was obtained by select experts to grade and calculate the weight coefficient. The weight of corresponding indexes at different levels can be calculated by combining the expert weight coefficient and the index matrix weight. As shown in Equation (30).

$$
\tilde{W}_{D-A}=(0.1166,0.0291,0.031,0.0243,0.1591,0.0325,0.0336,0.0734,0.0664,0.0887,0.1014,0.1333,0.1106)
$$

After calculating the comprehensive index weight, a combination of expert scoring method and membership function are used to quantify the evaluation indicators and determine the membership matrix of evaluation indicators.

\subsection{Experimental Result}

The resource and environmental emission results of various typical machine tools are collected through experiments, the collection method of machining process data is shown in Table 10. 
Table 10. Data collection method.

\begin{tabular}{cc}
\hline Data type & Method \\
\hline Processing parameters & Record on spot \\
Material consumption & Collected on spot, the difference in mass between parts before and \\
after processing \\
Tool/fixture wear & Qualitatively determine the tool/fixture wear on spot \\
Cool liquid consumption & $\begin{array}{c}\text { Convert according to usage time } \\
\text { Energy consumption }\end{array}$ \\
Dust & Ligital power meter (AWS2013) \\
Noise & Noise meter (TES-1352A) \\
Roughness & Surface roughness measuring instrument (MarSurf M300) or surface \\
Processing time & roughness comparing sample piece \\
Operation safety & Measurement on spot or recording time by digital power meter \\
Pungent odor & Observation and research on spot \\
& Observation and research on spot \\
\hline
\end{tabular}

Due to space issues, this part of the data (no-load time and processing time, chip and the material consumption are proportional to the relationship. The changes of coolant, fixture wear, dust, pungent odor and operation safety are not much or at the same level) are omitted.

Take the test number 1 of turning process as an example, the calculation process is as follows:

(1) total energy consumption $=$ no-load power $(5180 \mathrm{~W}) \times$ total time $(600 \mathrm{~s}+60 \mathrm{~s})+$ load power $(29 \mathrm{~W}) \times$ processing time $(600 \mathrm{~s})=3,436,200 \mathrm{~J}=0.955 \mathrm{kWh}$; Therefore, energy efficiency $=$ load power $(29 \mathrm{~W}) \times$ processing time $(600 \mathrm{~s}) /$ energy consumption $(3,436,200 \mathrm{~J})=0.51 \%$.

(2) carbon emission from energy consumption $=$ energy consumption $(0.955 \mathrm{kWh}) \times$ carbon emission factor of energy consumption $\left(0.499 \mathrm{kWh} / \mathrm{kgCO}_{2}\right)=477 \mathrm{~kg}$; carbon emission from material consumption = material consumption $(214 \mathrm{~g}) \times$ carbon emission factor of material consumption $\left(2.69 \mathrm{~kg} / \mathrm{kgCO}_{2}+0.31 \mathrm{~kg} / \mathrm{kgCO}_{2}\right)=642 \mathrm{~g}$; carbon emission from cool liquid consumption $=$ cool liquid consumption $(1.83 \mathrm{~g}) \times$ carbon emission factor of cool liquid consumption $\left(33.75 \mathrm{~kg} / \mathrm{kgCO}_{2}\right)=62 \mathrm{~g}$; Therefore, carbon efficiency = total carbon emission $(1181 \mathrm{~g}) /$ material removal volume $\left(27.26 \mathrm{~g} / \mathrm{cm}^{3}\right)=43 \mathrm{~g} / \mathrm{cm}^{3}$.

(3) green degree $=0.1166 \times$ material consumption (normalized value:6) $+0.0291 \times$ tool wear (normalized value:9.5) $+0.031 \times$ cool liquid consumption (normalized value:8) $+0.0243 \times$ fixture wear (normalized value:8) $+0.1591 \times$ energy consumption (normalized value:0) $+0.0325 \times$ dust (normalized value:5) $+0.0336 \times$ pungent odor (normalized value:9) $+0.0734 \times$ chips (normalized value:6) $+0.0664 \times$ waste liquid (normalized value:8) $+0.0887 \times$ noise (normalized value: 6.1$)+$ $0.1014 \times$ operation safety (normalized value:5) $+0.1333 \times$ processing time (normalized value:0) + $0.1106 \times$ roughness $($ normalized value: 9$)=4.90$.

The other results of energy efficiency, carbon efficiency and green degree during the typical machining process are calculated based on the presented model (since the rest of the content is similar, it is not presented here) and partial data are shown in Table 11. 
Table 11. Experimental results.

\begin{tabular}{|c|c|c|c|c|c|c|c|c|c|c|c|c|c|}
\hline $\begin{array}{l}\text { Machining } \\
\text { Process }\end{array}$ & $\begin{array}{c}\text { Test } \\
\text { Number }\end{array}$ & A & B & $\mathrm{C}$ & $\begin{array}{c}\text { Material } \\
\text { Consumption (g) }\end{array}$ & Tool Wear & $\begin{array}{c}\text { Energy } \\
\text { Consumption } \\
(\mathrm{kW} \cdot \mathrm{h})\end{array}$ & $\begin{array}{l}\text { Noise } \\
(\mathrm{db})\end{array}$ & $\begin{array}{l}\text { Processing } \\
\text { Time (s) }\end{array}$ & $\begin{array}{l}\text { Roughness } \\
(\mu \mathrm{m})\end{array}$ & $\begin{array}{c}\text { Energy } \\
\text { Efficiency (\%) }\end{array}$ & $\begin{array}{l}\text { Carbon } \\
\text { Efficiency } \\
\left(\mathrm{g} / \mathrm{cm}^{3}\right)\end{array}$ & $\begin{array}{c}\text { Green } \\
\text { Degree }\end{array}$ \\
\hline \multirow{6}{*}{ Turning } & 1 & 160 & 0.1 & 1 & 214 & small & 0.955 & 77.8 & 600 & $3.2-6.3$ & 0.51 & 43.33 & 4.90 \\
\hline & 2 & 160 & 0.2 & 1.5 & 320 & smaller & 0.481 & 78.2 & 300 & $3.2-6.3$ & 0.94 & 30.20 & 4.92 \\
\hline & 8 & 250 & 0.4 & 1 & 214 & general & 0.157 & 79.3 & 96 & 12.5 & 1.97 & 26.79 & 6.30 \\
\hline & 9 & 320 & 0.1 & 1.5 & 320 & smaller & 0.494 & 79.5 & 300 & 3.2 & 0.98 & 30.37 & 5.08 \\
\hline & 15 & 450 & 0.3 & 1 & 214 & general & 0.120 & 81.7 & 71 & 6.3 & 2.19 & 26.02 & 6.73 \\
\hline & 16 & 450 & 0.4 & 1.5 & 320 & larger & 0.091 & 83.5 & 53 & 12.5 & 3.36 & 24.80 & 5.84 \\
\hline \multirow{6}{*}{ Milling } & 1 & 190 & 75 & 3 & 156 & smaller & 0.216 & 73.5 & 126 & 12.5 & 0.75 & 29.65 & 5.02 \\
\hline & 2 & 190 & 95 & 4 & 208 & smaller & 0.174 & 73 & 100 & 12.5 & 1.10 & 27.22 & 5.25 \\
\hline & 8 & 235 & 75 & 4 & 208 & smaller & 0.209 & 74.4 & 126 & 12.5 & 0.89 & 27.99 & 4.60 \\
\hline & 9 & 300 & 95 & 3 & 156 & smaller & 0.177 & 74.6 & 100 & 12.5 & 0.79 & 28.52 & 5.40 \\
\hline & 15 & 375 & 118 & 3 & 156 & general & 0.140 & 74.1 & 80 & 12.5 & 1.17 & 27.48 & 5.82 \\
\hline & 16 & 375 & 150 & 4 & 208 & larger & 0.111 & 74.7 & 63 & 12.5 & 1.93 & 25.90 & 5.64 \\
\hline \multirow{6}{*}{ Planning } & 1 & 1200 & 0.3 & 4 & 31.06 & smaller & 0.141 & 68.2 & 83 & 12.5 & 21.51 & 43.58 & 4.94 \\
\hline & 2 & 1200 & 0.4 & 5 & 51.48 & smaller & 0.115 & 68.3 & 62 & 12.5 & 26.08 & 33.31 & 5.15 \\
\hline & 8 & 1500 & 0.6 & 4 & 61.77 & general & 0.072 & 69.8 & 33 & 12.5 & 26.92 & 28.57 & 5.62 \\
\hline & 9 & 1800 & 0.3 & 5 & 38.61 & smaller & 0.111 & 69.5 & 55 & 12.5 & 21.64 & 35.99 & 5.47 \\
\hline & 15 & 2100 & 0.5 & 4 & 51.48 & general & 0.071 & 70.5 & 28 & 12.5 & 23.70 & 29.41 & 5.92 \\
\hline & 16 & 2100 & 0.6 & 5 & 77.22 & general & 0.061 & 71.1 & 23 & 12.5 & 26.91 & 26.93 & 5.67 \\
\hline \multirow{6}{*}{ Grinding } & 1 & 160 & 0.1 & 1 & 0.35 & small & 0.038 & 67.1 & 18 & 0.105 & 0.39 & 486.35 & 5.83 \\
\hline & 2 & 160 & 0.2 & 1.5 & 0.7 & smaller & 0.019 & 66.9 & 9 & 0.132 & 0.71 & 139.86 & 6.66 \\
\hline & 8 & 250 & 0.4 & 1 & 1.05 & general & 0.010 & 66.3 & 4.5 & 0.172 & 1.51 & 63.00 & 7.20 \\
\hline & 9 & 320 & 0.1 & 1.5 & 1.05 & smaller & 0.039 & 71.3 & 18 & 0.139 & 0.75 & 182.68 & 4.96 \\
\hline & 15 & 450 & 0.3 & 1 & 0.7 & general & 0.013 & 66.9 & 6 & 0.155 & 1.68 & 104.63 & 7.29 \\
\hline & 16 & 450 & 0.4 & 1.5 & 0.35 & larger & 0.010 & 65.4 & 4.5 & 0.152 & 2.58 & 146.48 & 7.90 \\
\hline \multirow{6}{*}{ Drilling } & 1 & 200 & 0.06 & 8 & 31.55 & small & 0.102 & 65.4 & 79 & 6.3 & 0.44 & 38.23 & 5.32 \\
\hline & 2 & 200 & 0.1 & 10 & 49.3 & smaller & 0.078 & 65.3 & 60 & 6.3 & 0.65 & 30.72 & 5.46 \\
\hline & 8 & 250 & 0.16 & 8 & 31.55 & general & 0.040 & 65.3 & 30 & 6.3 & 0.75 & 29.26 & 6.66 \\
\hline & 9 & 320 & 0.06 & 10 & 49.3 & smaller & 0.065 & 65.6 & 49 & 6.3 & 0.68 & 29.49 & 5.75 \\
\hline & 15 & 400 & 0.13 & 8 & 31.55 & general & 0.031 & 68.7 & 23 & 6.3 & 0.97 & 27.94 & 6.90 \\
\hline & 16 & 400 & 0.16 & 10 & 49.3 & larger & 0.026 & 66.9 & 19 & 6.3 & 1.37 & 25.92 & 6.81 \\
\hline
\end{tabular}




\section{Discussion}

\subsection{Study on the Influence of Processing Parameters}

The main effect analysis is conducted on the data in the table in order to analyze the influence of processing parameters on energy efficiency, carbon efficiency and green degree and the main effect analysis results by the Minitab software (R17, Pennsylvania State University, Philadelphia, PA, USA, 2014) are shown in Figure 6.

1. Energy efficiency: from the results of A1-E1 in Figure 6, it can be seen that the effect of processing parameters on energy efficiency is basically the amount of the back engagement (drilling diameter) $\approx$ feed (feed rate) $>$ spindle speed. As the spindle speed, feed (feed rate) and back engagement (hole diameter) increases, the energy efficiency will also increases, because, when the processing parameters increases, the material removal energy consumption increases, in other words, the effective energy consumption part increases, the ratio of the remaining total energy consumption increases, thus, the energy efficiency increases accordingly (As shown in Figure $6 \mathrm{C} 1$, the spindle speed is inversely proportional to energy efficiency in the planning process, because planning is far higher than other machining process, the energy efficiency reached $30 \%$ which lead to the spindle speed growth rate faster than the ratio of rate).

2. Carbon efficiency: from the results of A2-E2 in Figure 6, it can be seen that the effect of processing parameters on carbon efficiency is basically the amount of the feed (feed rate) $>$ back engagement (drilling diameter) > spindle speed. As the spindle speed, feed (feed rate) and back engagement (hole diameter) increases, the carbon efficiency will decrease, because, increasing processing parameters increases the material removal power but also reduces processing time, thereby reducing carbon emission and increasing carbon efficiency. In addition, the increase of the back engagement will increase the material removal volume, thus, the impact degree of the back engagement is small.

3. Green degree: from the results of A3-E3 in Figure 6, it can be seen that the green degree of the machining process is positively correlated with the spindle speed and feed (feed rate) and it has a negative correlation with the back engagement (drilling diameter). The main reason is that increasing the amount of back engagement (drilling diameter) will greatly increase the consumption of raw material and produce plenty of attle, which play a large weight in the green degree. Increasing spindle speed and feed (feed rate) will reduce processing time, energy consumption and emission, thus presenting positive correlation (As shown in Figure 6C3, because the grinding process is precision machining and the resource consumption is small, the influence on spindle speed and grinding depth is not significant). 


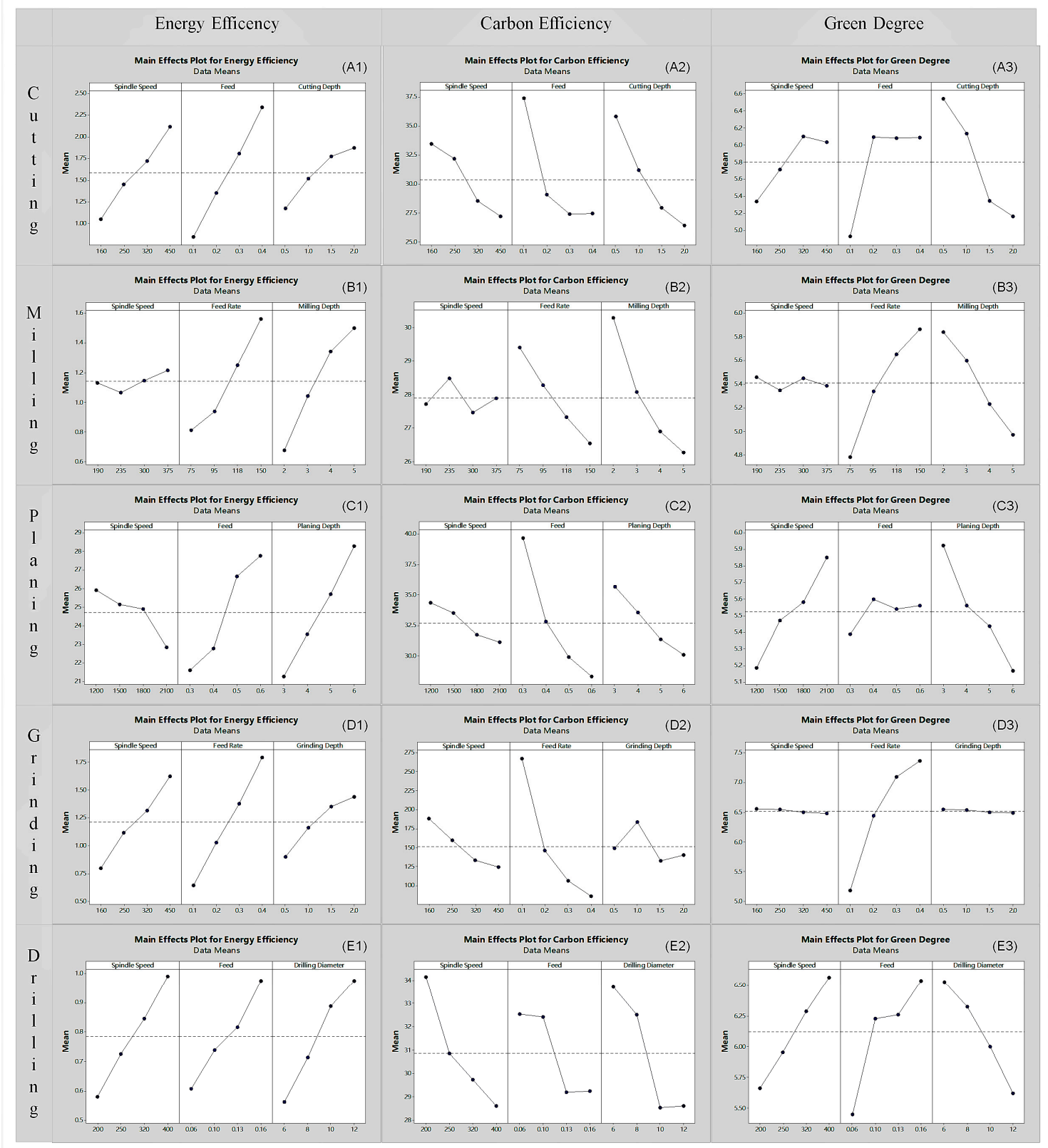

Figure 6. Main effects plot for energy efficiency, carbon efficiency and green degree.

\subsection{Comparative Analysis of Energy Efficiency, Carbon Efficiency and Green Degree}

The following conclusions can be drawn from the analysis of experimental data.

1. The energy efficiency of different machine tools and different machining processes are different. Generally speaking, the energy efficiency of the CNC machines is relatively higher than the manual machines due to the various energy dissipation structures. For example, the maximum energy efficiency of the $\mathrm{X} 62 \mathrm{~W}$ universal knee-type milling machine is $1.93 \%$ and the maximum energy efficiency of the MGK7120 CNC surface grinder is $2.58 \%$. The drilling machine is relatively low in energy efficiency compared with the CNC machine due to the simple manual main drive system. The average energy efficiency of BM2015 gantry planer is more than $30 \%$, which is far higher than the general machine tool. Planning is a kind of rough machining, with large amount of material removal and high load power, which can be used to material removal energy consumption. 
2. The carbon efficiency of different machine tools and machining processes with little difference. Carbon efficiency maintained within 20 to $50 \mathrm{~g} / \mathrm{cm}^{3}$. The grinding process is much large than other processes, mainly due to less material removal and long processing time in the precision machining.

3. The green degree of different machine tools and different machining processes. There is no significant difference in green degree under various conditions and parameters but it shows the difference between different schemes, which is related to the average division between each index weight. At the same time, it can be seen that the maximum green degree value is only 7.67, a barely satisfactory result, which is generally related to the general operational process security and high roughness value of this series of experiments.

4. It can be seen from the results that there is a certain similarity in the ranking of processing parameters with the highest energy efficiency, optimal carbon efficiency and the best green degree, which is consistent with the theoretical results. The feasibility and practicability of the energy efficiency model, carbon efficiency model and green degree model are verified.

\subsection{Research on Strategies of Energy Conservation and Emission Reduction}

In order to realize energy conservation and emission reduction in manufacturing process, the following strategies combining with experimental results are proposed:

1. Reasonable selection of machine tool energy source. The energy source efficiency of CNC machine tool is higher than that of ordinary machine tool. Therefore, in the actual machining process, the high-efficiency energy source is used to replace the high-consumption energy source, so as to reduce the energy consumption of the machine tool itself and achieve the purpose of energy conservation.

2. Automatic start-stop setting for auxiliary equipment. In this paper, BM2015 gantry planer consumes more energy because its auxiliary equipment is opened more. Therefore, in the actual machining process, the automatic start-up device of auxiliary equipment is installed to improve the automation degree of machine tools, so as to improve the efficiency of machine tools and achieve the purpose of energy conservation.

3. Integration of resource and environment information. With the support of shared information model, basic resources environmental database and knowledge base are established related to contain energy consumption and carbon emission by using communication technology and database technology to realize green manufacturing information sharing and use in manufacturing process.

4. Optimized configuration of machining process. Enterprises generally with low energy utilization rate and insufficient utilization of energy effective in the production and manufacturing process. The effective solutions through reasonable allocation of the machining process scheme and effective scheduling of the machining process should be taken to optimize the management and control of energy and resources in the machining process, so as to reduce energy consumption, improve carbon efficiency and green degree.

5. Reasonable selection of processing parameters. The energy consumption decreases with the increase of material removal rate, large process parameters should be selected as far as possible to obtain lower unit cutting energy consumption and higher energy efficiency. Using large process parameters can shorten the processing time, reduce the total energy consumption and carbon emission and on the other hand increase the amount of metal removal per unit time. Tool wear, workpiece calorific value and total energy consumption of machine tool is bigger under the condition of dry cutting, these factors influence on the per unit cutting energy consumption and energy efficiency significantly, which inhibit the process parameter values to improve the energy efficiency. Considering the high energy consumption of standby and no-load state of machine 
tools, the standby and no-load energy consumption of machine tool should be reduced as much as possible when designing machine tools and the standby and no-load time should be reduced.

\section{Conclusions}

Machine tools are the most basic tools and wildly used in machining process, which consumes amount of energy and emission. In order to meet the needs of energy-saving production and low-carbon manufacturing, this paper points out the problem that the sustainable manufacturing model is not practical and comprehensive. Based on the theory and experiment, the hierarchical modeling and parameter impact analysis of the green manufacturing of machine tools are carried out and the following conclusions are obtained:

1. The energy consumption of startup state, standby state, no-load state and load state is depended on machine tools, the two parts are mainly determined by the structure of the machine tool itself. Based on the experimental analysis, it is concluded that the no-load power material removal power is exponentially related to the processing parameters and these models can be used to predict the energy consumption and energy efficiency. In addition, other machine tools need to be re-tested to determine the correlation coefficient.

2. The carbon emission from machining process is consisted of electric energy and material consumption, which can be calculated by combining relevant carbon emission factor data. The difference in carbon efficiency in this paper is mainly reflected in dry cutting and precision machining.

3. Green degree calculation method combines fuzzy analytic hierarchy process and fuzzy comprehensive evaluation method, which Overcomes the influence of subjective evaluations of different experts can make the evaluation results more objective and accurate. It is preferred to have a set of process parameters with the best green degree value, which is of great significance for improving the greenness of the process and realizing the green manufacturing process.

4. The traditional processing parameters selection are more conservative, the experimental results showed that adjusting the amount of back cutting depth can better achieve energy saving and emission reduction while under the limitation of machining quality.

The application of this work is that the proposed models can be used for the analysis, calculation and evaluation of the green performance of the machining system. Furthermore, the next step is to study the process parameter optimization of the machining process aiming at the highest greenness and the comprehensive optimization model of the efficient and low-carbon operation of the machining system.

Author Contributions: Conceptualization, L.L. and Z.D.; Methodology, L.L.; Software, T.L.; Validation, L.L., Z.D. and L.W.; Formal Analysis, L.L.; Investigation, H.Y., T.Z. and W.H.; Writing-Original Draft Preparation, L.L.; Writing-Review \& Editing, Z.D. and L.W.

Funding: This research was funded by the National Natural Science Foundation of China, grant number U1809221, Green Manufacturing System Integration Project of China and Industrial Technology Collaborative Innovation Special Funds Project of Xiangtan, grant number C11811.

Conflicts of Interest: The authors declare no conflicts of interest.

\section{References}

1. Dornfeld, A. Green Manufacturing; Springer: New York, NY, USA, 2013.

2. The International Academy for Production Engineering. 26th International Manufacturing Conference. Available online: http:/ / internationalmanufacturingconference.com/ (accessed on 30 December 2018).

3. Gutowski, T. Electrical energy requirements for manufacturing processes. In Proceedings of the 13th CIRP International Conference on Life Cycle Engineering, Leuven, Belgium, 31 May-2 June 2006; Volume 5, pp. 560-564. 
4. EPTA. Study for Preparing the First Working Plan of the Eco-design Directive. Available online: http: / / ec.europa.eu/enterprise/policies/sustainable-business / files / workingplan_finalreport_en.pdf (accessed on 30 December 2018).

5. Cai, W.; Lai, K.; Liu, C.; Wei, F.; Ma, M.; Jia, S.; Jiang, Z.; Lv, V. Promoting sustainability of manufacturing industry through the lean energy-saving and emission-reduction strategy. Sci. Total Environ. 2019. [CrossRef] [PubMed]

6. Zhou, L.; Li, J.; Li, F.; Meng, Q.; Li, J.; Xu, X. Energy consumption model and energy efficiency of machine tools: A comprehensive literature review. J. Clean. Prod. 2016, 112, 3721-3734. [CrossRef]

7. Zhang, Y. Energy efficiency techniques in machining process: A review. Int. J. Adv. Manuf. Technol. 2014, 71, 1123-1132.

8. Wang, Q.; Liu, F. An integrated method for assessing the energy efficiency of machining workshop. J. Clean. Prod. 2013, 52, 122-133. [CrossRef]

9. Bhushan, R.K. Optimization of cutting parameters for minimizing power consumption and maximizing tool life during machining of $\mathrm{Al}$ alloy $\mathrm{SiC}$ particle composites. J. Clean. Prod. 2013, 39, 242-254. [CrossRef]

10. Peng, T.; Xu, X. Energy-efficient machining systems: A critical review. Int. J. Adv. Manuf. Technol. 2013, 72, 1389-1406. [CrossRef]

11. Duflou, R.; Sutherland, J.; Dornfeld, D. Towards energy and resource efficient manufacturing: A processes and systems approach. CIRP Ann. Manuf. Technol. 2012, 61, 587-609. [CrossRef]

12. Jeswiet, J.; Kara, S. Carbon emissions and CEStm in manufacturing. CIRP Ann. Manuf. Technol. 2008, 57, 17-20. [CrossRef]

13. Hindiyeh, M.; Altalafha, T.; Al-Naerat, M.; Saidan, H.; Al-Salaymeh, A.; Sbeinati, L.; Saidan, M.N. Process Modification of Pharmaceutical Tablet Manufacturing Operations: An Eco-Efficiency Approach. Processes 2018, 6, 15. [CrossRef]

14. Mi, Y.; Zheng, D.; Jiang, X. Multi-product carbon footprint assessment for low-rank coal-based acetylene manufacturing process. J. Clean. Prod. 2008, 112, 1676-1682. [CrossRef]

15. Li, H.; Cao, H. A carbon emission analysis model for electronics manufacturing process based on value-stream mapping and sensitivity analysis. Int. J. Comput. Integr. Manuf. 2012, 25, 1102-1110. [CrossRef]

16. Zhou, G.; Yuan, S.; Lu, Q.; Xiao, X. A carbon emission quantitation model and experimental evaluation for machining process considering tool wear condition. Int. J. Adv. Manuf. Technol. 2018, 98, 565-577. [CrossRef]

17. Li, C.; Tang, Y.; Cui, L.; Li, P. A quantitative approach to analyze carbon emissions of CNC-based machining systems. J. Intell. Manuf. 2015, 26, 911-922. [CrossRef]

18. Deng, Z.; Lv, L. Study on the model of high efficiency and low carbon for grinding parameters optimization and its application. J. Clean. Prod. 2016, 137, 1672-1681. [CrossRef]

19. Li, B.; Cao, H.; Yan, J.; Jafar, S. A life cycle approach to characterizing carbon efficiency of cutting tools. Int. J. Adv. Manuf. Technol. 2017, 93, 1-9. [CrossRef]

20. Cao, H.; Li, H. Simulation-based approach to modeling the carbon emissions dynamic characteristics of manufacturing system considering disturbances. J. Clean. Prod. 2014, 64, 572-580. [CrossRef]

21. Cheng, H.-Q.; Cao, H.-J.; Li, H.-C.; Luo, Y. Decision-making model of mechanical components based on carbon benefit and its application. Comput. Integr. Manuf. Syst. 2013, 19, 2018-2025.

22. Cai, W.; Liu, C.; Zhang, C.; Ma, M.; Rao, W.; Li, W.; He, K.; Gao, M. Developing the ecological compensation criterion of industrial solid waste based on emergy for sustainable development. Energy 2018, 157, 940-948. [CrossRef]

23. Yeo, S.; Neo, K. Inclusion of environmental performance for decision making of welding processes. J. Mater. Process. Technol. 1998, 82, 78-88. [CrossRef]

24. Wang, X.; Gu, X.; Liu, Z.; Wang, Q.; Xu, X.; Zheng, M. Production Process Optimization of Metal Mines Considering Economic Benefit and Resource Efficiency Using an NSGA-II Model. Processes 2018, 6, 228. [CrossRef]

25. Hui, I.; Lau, H.C.W.; Chan, H.S.; Lee, K.T. An Environmental Impact Scoring System for Manufactured Products. Int. J. Adv. Manuf. Technol. 2002, 19, 302-312. [CrossRef]

26. Wang, Y.; Zhang, H.; Jiang, Z.; Zhao, G. Data analysis and evaluation system for resource and environmental attributes in the manufacturing process. Int. J. Comput. Integr. Manuf. 2014, 27, 372-381. [CrossRef]

27. Govindan, K.; Kannan, D. Evaluating the drivers of corporate social responsibility in the mining industry with multi-criteria approach: A multi-stakeholder perspective. J. Clean. Prod. 2014, 84, 214-232. [CrossRef] 
28. Rostamzadeh, R. Application of fuzzy VIKOR for evaluation of green supply chain management practices. Ecol. Indic. 2015, 49, 188-203. [CrossRef]

29. Liu, F.; Wang, Q.; Liu, G. Content Architecture and Future Trends of Energy Efficiency Research on Machining Systems. J. Mech. Eng. 2013, 49, 87. [CrossRef]

30. Liu, F.; Xie, J.; Liu, S. A method for predicting the energy consumption of the main driving system of a machine tool in a machining process. J. Clean. Prod. 2013, 105, 171-177. [CrossRef]

31. Liu, F.; Liu, P.; Li, C.; Tuo, J.; Cai, W. The Statue and Difficult Problems of Research on Energy Efficiency of Manufacturing Systems. J. Mech. Eng. 2017, 53, 1-11. [CrossRef]

32. Li, C.; Cui, L.; Liu, F.; Li, L. Multi-objective nc machining parameters optimization model for high efficiency and low carbon. J. Mech. Eng. 2013, 49, 87-96. [CrossRef]

33. Liu, F.; Xu, Z.J.; Dan, B.; Zan, X. Energy Performance of Mechanical Processing System and Application; China Machine Press: Beijing, China, 1995.

34. Agapiou, J.S. The Optimization of Machining Operations Based on a Combined Criterion, Part 1: The use of combined objectives in single pass operations. Trans. ASME 1992, 114, 500-507. [CrossRef]

35. Narita, H.; Kawamura, H.; Norihisa, T.; Lian-yi, C.H.E.N.; Fujimoto, H.; Hasebe, T. Development of Prediction System of Environmental Burden for Machine Tool Operation (2nd Report, Proposal of Evaluation Indicator for Eco-Efficiency). JSME Int. J. 2006, 71, 1392-1399.

36. Narita, H.; Kawamura, H.; Norihisa, T.; Chen, L.Y.; Fujimoto, H.; Hasebe, T. Development of Prediction System of Environmental Burden for Machine Tool Operation: 1st Report, Proposal of Calculation Method of Environmental Burden. Trans. Jpn. Soc. Mech. Eng. C 2006, 71, 923-928. [CrossRef]

37. China institute of standardization. Greenhouse Gas Emission Quantification and Report for Enterprise; China Zhijian Publishing House: Beijing, China, 2011.

38. Hur, T.; Kim, I. Measurement of green productivity and its improvement. J. Clean. Prod. 2004, 12, 673-683. [CrossRef]

39. Linton, J. DEA: A Method for Ranking the Greeness of Design Decisions. J. Mech. Des. 2002, 124, $145-150$. [CrossRef]

40. Zhang, J. Fuzzy Analytical Hierarchy Process. Fuzzy Syst. Math. 2000, 14, 80-88.

41. Saaty, T. The Analytic Hierarchy Process; McGraw-Hill: New York, NY, USA, 1980. 